\title{
Creatine Phosphokinase and Visual Analogue Scale as Indicators for Muscle Injury in Untrained Bodybuilders
}

\author{
Suresh Shanmugam, ${ }^{1}$ Reni Farenia, ${ }^{2}$ Nina Tristina ${ }^{3}$ \\ ${ }^{1}$ Faculty of Medicine Universitas Padjadjaran, ${ }^{2}$ Department of Physiology Faculty of Medicine \\ Universitas Padjadjaran, ${ }^{3}$ Department of Clinical Pathology Faculty of Medicine Universitas \\ Padjadjaran/Dr. Hasan Sadikin General Hospital Bandung
}

\begin{abstract}
Background: Skeletal muscle is a vital tissue in the human body to enable breathing, walking and performing several sports activities. However, this muscle is persistently injured throughout every sports session. Some exercises demand a muscle injury occurrence in order to build a stronger muscle through an adaptation process namely bodybuilding exercise. Importantly, every muscle injury should occur within a physiological range which can be identified by several biomarkers as well as pain scale. The aim of this study was to identify changes on the level of Creatine phosphokinase (CPK) and Visual analogue scale (VAS) between pre and post training sessions and the correlation between these two indicators.

Methods: This was an observational analytical cross sectional comparison study which was conducted in October 2012 and the subjects were adult untrained bodybuilders at the Jatinangor fitness center. The data was obtained by measuring serum CPK and marked VAS. The data were analyzed by t-test, Wilcoxon's test and Spearman's correlation.

Results: Both CPK and VAS increased significantly by $296 \mathrm{U} / \mathrm{L}$ and $19.9 \mathrm{~mm}$ respectively. There was a strong positive significant correlation between VAS and CPK $(\mathrm{p}=0.01, \mathrm{r}=0.711)$.

Conclusion: The healthy untrained bodybuilders chosen in this study experienced a mild $(<2000$ U/L) muscle injury throughout the training sessions with general increased CPK levels and VAS measurement. [AMJ.2015;2(1):147-52]
\end{abstract}

Keywords: Infra orbital foramen, palpation technique, superfacial marking technique

\section{Introduction}

Skeletal muscle is vital tissue in the human body as its function is to enable the body to perform various activities including sports. However, this muscle is persistently injured throughout every exercise session which requires high force eccentric and concentric contractions and this is even magnified in an unaccustomed exercise. Thus, muscle injury is initiated with physical disruption of muscle components involving in generating and transmitting force ${ }^{1}$.

There are many impacts on skeletal muscle during strenuous exercises including disruption of sarcomeres, cytoskeleton component, injury to muscle cell membrane and impairment of excitation contraction coupling process which eventually cause the loss of muscle ability to produce sufficient force. Besides that, there will be increase in resting intracellular calcium level, presence of inflammatory reaction which causes breakdown of muscle content comprising of cell proteins and enzymes ${ }^{2}$.

However, the injured skeletal muscle will return to normal condition through repairing process if the injury occurs within physiological range. Bodybuilding exercise is a type of exercise that demands muscle injury occurrence through resistance training in order to build stronger muscle by adapting to increasing training intensity. ${ }^{2}$

The adaptation process is very important in untrained bodybuilders or the beginners, as this period is imperative in giving appropriate precursor for the occurrence of muscle adaptation. In the acute phase of adaptation which occurs during exercise and immediately after the end of exercise it causes muscle soreness as well as increased serum level of intracellular enzymes and release of muscle fiber content into circulation. Currently, there is

Correspondence: Suresh Shanmugam, Faculty of Medicine, Universitas Padjadjaran, Jalan Raya Bandung-Sumedang Km.21, Jatinangor, Sumedang, Indonesia, Phone: +628170208187 Email : Suresh2889@yahoo.com.my 
no clear consensus regarding the exact level of biomarkers level in determining overtraining status in untrained bodybuilders. ${ }^{3}$

Creatine phosphokinase (CPK) enzyme is able to breakdown creatine by consuming adenosine triphosphate (ATP) to form phosphocreatine which gives high energy to skeletal muscle aiding in producing greater force. Besides that, this enzyme is often used as serum biomarker for detecting muscle injury with high sensitivity, and its ability to stay in circulation for 24 hours to 48 hours compare to other biomarkers. ${ }^{4}$ The normal level of CPK is <200 U/L but the elevation of CPK is considered normal in exercise, however it can be further classified into mild $(<2000 \mathrm{U} / \mathrm{L})$, moderate $(2000-10,000 \mathrm{U} / \mathrm{L})$ and severe $(>10,000 \mathrm{U} / \mathrm{L})$. No studies so far have established a normal range following an exercise period but the risk of kidney injury occurs when the level of CPK is above 6000 U/L.5 The evaluation of muscle soreness that becomes prominent after exercise can be performed using the visual analogue scale (VAS) which is helpful in assessing pain intensity by marking on a vertical line of $10 \mathrm{~cm}$ line with both clearly marked edges. ${ }^{6}$

Based on these, this research was conducted to evaluate the level of CPK and VAS value before and after bodybuilding exercise in untrained bodybuilders as well as to find correlation between CPK and VAS in untrained bodybuilders.

\section{Methods}

The research was approved by the Health Research Ethic Committee of Faculty of Medicine, Universitas Padjadjaran. Inform consent was obtained from 12 male untrained bodybuilders aged 17 ?20 years old. The bodybuilders were chosen with the criteria of minimum 8 hours training per week during one month and the attendance was taken throughout their training sessions. All the subjects were refrained to participate in any strenuous activity 24 hours prior to measurement as well as history of simvastatin drug intake and alcohol consumption prior to measurement. Besides that, the subjects who participated in this study were free of supplement usage during one month.

An appropriate and experienced lab assistant was chosen for withdrawing blood samples. Venous blood samples (3 cc) from brachial vein were obtained before and after bodybuilding exercise. The subjects underwent 1.5 hours training using maximum repetition (1RM) technique for 3 sets comprises $5 \mathrm{~kg}, 10$ $\mathrm{kg}, 12 \mathrm{~kg}$ until failure with minimum of 8 repetitions in each set. The subjects underwent training involving bench press, lateral raises, chest flyes, shoulder press, upright rows, leg curl, leg extension, leg press, pull-down, and crunches.

The blood samples were analyzed on the same day of collection and the samples were stored at $-20^{\circ} \mathrm{c}$ until analysis using a spectrophotometer. The marked line by the subjects in VAS was measured using a ruler in millimeter (mm). Both blood samples for the CPK examination and VAS measurement were taken 30 minutes before exercise and at 24 hours after exercise to measure pre and post measurements, respectively. Besides that, heart rate (HR) and blood pressure (BP) were also taken before and after exercise period. The flow of research is depicted in Figure 1. The data were analyzed by Shapirowilk's test, Wilcoxon's test, t-test, and Spearman's correlation statistical test between variables.

\section{Results}

The data on CPK and BP were not normally distributed $(\mathrm{p}<0.05)$ whereas HR and VAS were normally distributed with $p>0.05$. Thus, data on CPK and BP were analyzed using Wilcoxon's test (non-parametric) and VAS and HR using t-test (parametric). The median for pre CPK was $281 \mathrm{U} / \mathrm{L}$, that was increased up to $577 \mathrm{U} / \mathrm{L}$ in post $\mathrm{CPK}(\mathrm{p}=0.003)$. The result on the CPK data is shown in Table 1.

The mean for VAS increased significantly $(\mathrm{p}<<0.001$ ) from $31.7 \mathrm{~mm}$ in pre to $51.6 \mathrm{~mm}$ in post exercise. The difference of VAS value between pre and post exercise was $19.9 \mathrm{~mm}$ and is shown in Table 2.

In addition, Table 3 shows that the HR increased significantly about 39 beats/min

Table 1 Result of Wilcoxon's test Pre-Post CPK for $n=12$

\begin{tabular}{ccccccc}
\hline CPK (U/L) & Median & Min & Max & Range & Z & p-value \\
\hline Pre(30minutes) & 281 & 143 & 6812 & 6669 & 2,981 & 0.003 \\
Post(24 hours) & 577 & 275 & 34090 & 33815 & & \\
\hline
\end{tabular}




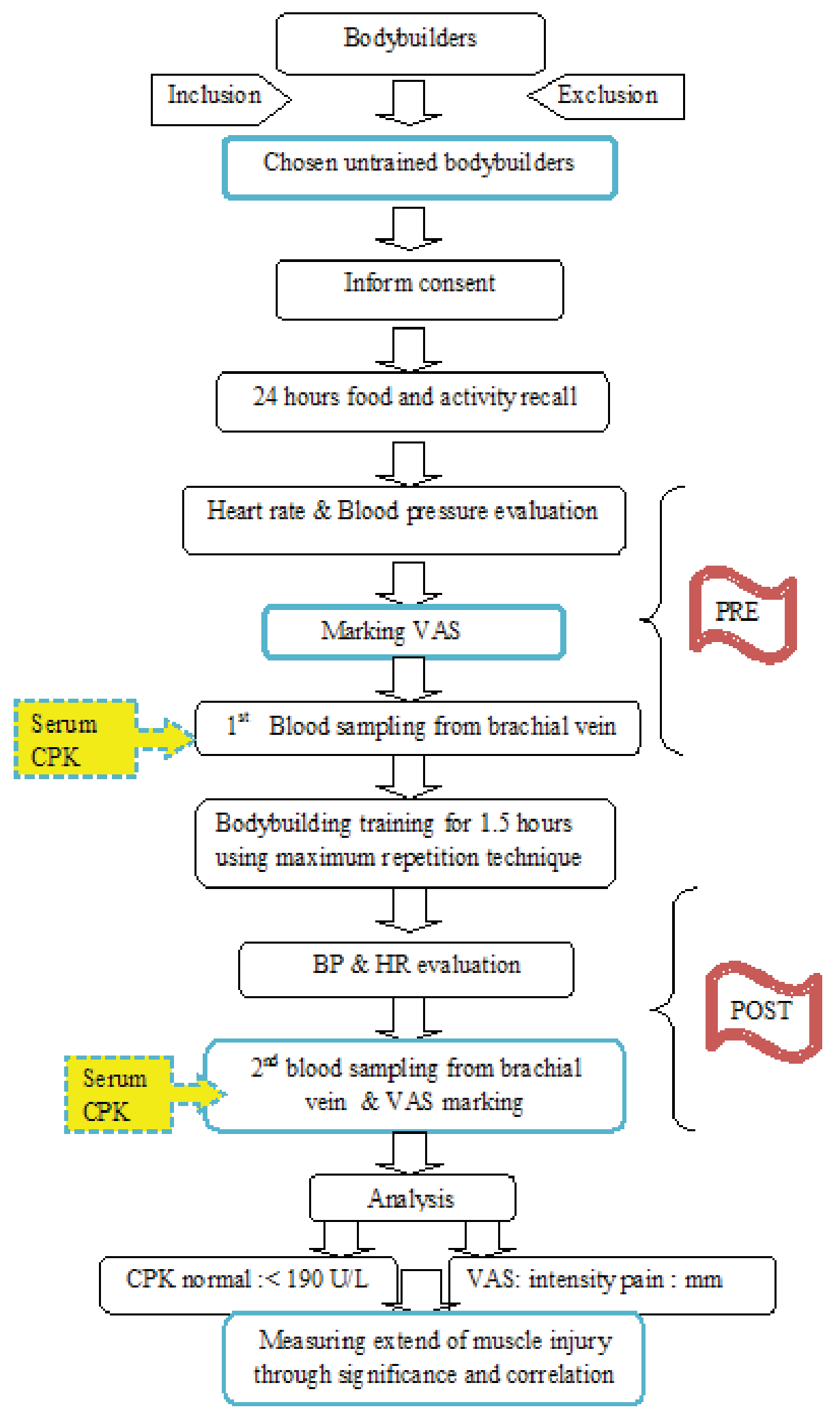

Figure 1 Research Flows

Althea Medical Journal. 2015;2(2) 
Table 2 Result of $t$-test for pre and post VAS for $n=12$

\begin{tabular}{cccccccc}
\hline $\begin{array}{c}\text { HR } \\
\text { (beats } / \text { min) }\end{array}$ & $\begin{array}{c}\text { Standard } \\
\text { Deviation }\end{array}$ & Min & Max & $\begin{array}{c}\text { Mean } \\
\text { (X) }\end{array}$ & Range & t & p-value \\
\hline $\begin{array}{c}\text { Pre } \\
\text { (30minutes) }\end{array}$ & \pm 23.7 & 2.0 & 80.0 & 31.7 & 78.0 & 4,834 & $<0.001$ \\
$\begin{array}{c}\text { Post } \\
(24 \text { hours })\end{array}$ & \pm 18.7 & 19.0 & 93.0 & 51.6 & 74.0 & & \\
\hline
\end{tabular}

or $36.4 \%(\mathrm{p}<0.001)$ from pre to post exercise. Table 4 shows data on BP revealed the systole increased from pre to post $(\mathrm{p}=0.034)$ whereas diastole increased about $5 \mathrm{~mm} / \mathrm{Hg}(\mathrm{p}=0.009)$.

The correlation between CPK and VAS revealed that it was positively correlated in untrained body builders (r-value;-0.711; with strong correlation: $\mathrm{p}$-value $=0.01$ ).

\section{Discussions}

CPK is often used as marker to indicate muscle damage in athletes and most effective tools in evaluating sports performance. ${ }^{7}$ Based on the CPK data, there were only 2 out of 12 untrained bodybuilders who had normal $(<190$ $\mathrm{U} / \mathrm{L}$ ) during pre-training period measurement with $143 \mathrm{U} / \mathrm{L}$ and $159 \mathrm{U} / \mathrm{L}$ respectively. Though all the subjects had been chosen based on exclusion criteria, yet the CPK value before training sessions failed to return to normal level. However, this situation is considered normal for an individual who participates in resistance training comprises eccentric and concentric movements. Besides that CPK elevation is still considered physiologic if the subjects never complain of renal failure symptoms such as decrease urine output or color changes as well as the CPK upper limit is less than $10,000 \mathrm{U} / \mathrm{L}^{8}$

There was only 1 subject in this study who had the highest pre training CPK level with $6812 \mathrm{U} / \mathrm{L}$. All the 12 subjects had significantly elevated CPK levels during post training measurements and mostly under mild $(<2000$ U/L) elevation except one subject who was under severe level of 34,090 U/L. Though 1 subject had high pre training CPK and had severe elevated CPK post training, yet complains regarding renal failure symptoms was not encountered because kidney failure would not develop only based on CPK level because co-morbid situation such as sepsis, dehydration, and acidosis could contribute to this situation. ${ }^{9}$

Majority of the subjects in this study had developed some point of adaptation to training with proven mildly elevated CPK level and adaptation period usually occurred within 4 to 10 days in the first week of training. The level of CPK in untrained bodybuilders is highly dependent on the period of rest between training sessions as this will reduce the lymphatic transport and release of enzyme from muscle fibers. Besides period of rest, there are other factors such as intensity, training volume, hydration, and clearance level of CPK from blood systems.

The elevation of CPK in this study was within physiological limit because all the subjects underwent training sessions without difficulties that debilitate them. Physiologically, each training will damage skeletal muscle at the level of sarcolemma and $\mathrm{Z}$ disks when the loading is higher than muscle ability. ${ }^{4,10}$ Therefore, subjects with the highest level of CPK indirectly also indicate the lower muscle adaptation level, usually adaptation occurs with more recruitment of sarcomeres

Table 3 Result of Paired t-test for Pre and Post Heart Rate (HR) for $\mathbf{n = 1 2}$

\begin{tabular}{cccccccc}
\hline $\begin{array}{c}\text { HR } \\
\text { (beats/min) }\end{array}$ & $\begin{array}{c}\text { Standard } \\
\text { Deviation }\end{array}$ & Min & Max & $\begin{array}{c}\text { Mean } \\
(\mathbf{X})\end{array}$ & Range & t & p-value \\
\hline $\begin{array}{c}\text { Pre } \\
(10 \text { minutes })\end{array}$ & \pm 6 & 62 & 80 & 68 & 18 & 11,710 & $<0.001$ \\
$\begin{array}{c}\text { Post } \\
(2 \text { minutes })\end{array}$ & \pm 13 & 90 & 132 & 107 & 42 & & \\
\hline
\end{tabular}


Table 4 Result of Wilcoxon's test on BP for pre and post $(n=12)$

\begin{tabular}{ccccccc}
\hline BP(mm/Hg) & Median & Minimum & Maximum & Range & $\mathbf{Z}$ & p-value \\
\hline Pre Systole & 120 & 110 & 130 & 20 & 2.212 & 0.034 \\
Post systole & 120 & 115 & 130 & 15 & & \\
Pre diastole & 80 & 70 & 90 & 20 & 2.598 & 0.009 \\
Post diastole & 85 & 75 & 90 & 15 & & \\
\hline
\end{tabular}

and signaling molecules. ${ }^{10}$ The adaptation to training can be obtained easily by increasing endurance training than strength training in early period as this will give good precursor for muscle development with appropriate amount of pro-inflammatory factors..$^{10}$

Almost all the untrained bodybuilders who underwent training exhibited some changes in VAS though it was rather subjective compared to CPK. The soreness experienced by the subjects following training is due to presence of inflammatory mediators. ${ }^{11}$ The VAS data showed average pain intensity increased from $31.71 \mathrm{~mm}$ to $51.75 \mathrm{~mm}$ post exercise. In pre training, some subjects showed to have lesser pain $(<10 \mathrm{~mm})$ though some even had the highest level of pain with $80 \mathrm{~mm}$. This is because the adaptation process and improper technique influence the soreness experienced by the subjects. ${ }^{11}$

The strong positive significant correlation existence between CPK and VAS has been proven in this study. The subjects with the highest pre and post CPK level had shown to have the highest VAS. The possible explanation is damage which occurs at sarcomere mainly at contractile filaments and Z fibers causes excitation coupling dysfunctions and ends in loss of calcium homeostasis within skeletal muscle. ${ }^{12,13}$ Eventually, this whole process initiates an autogenic process that results in elevated white blood cells and inflammatory mediators. These factors are able to damage the plasma lemma, endomysium, epimysium and perimysium which cause outpouring of muscle enzymes into circulation from proteolytic activity. ${ }^{1,13}$ Moreover, the substance released from an autogenic process are able to give stimulation to free nerve ending around muscle cells itself. Therefore, the untrained bodybuilders who are still in an early period of bodybuilding exercise experience higher level of soreness and this highlights the importance for higher intensity of soreness in untrained bodybuilders to be evaluated for serum CPK level to measure severity of muscle damage. ${ }^{14}$

Some subjects who exhibit small increase $\mathrm{l}$ of CPK and VAS may have undergone great adaptation. The reason for adaptation lies in the level of reactive oxygen species (ROS) produced of which higher level of ROS may give negative effect to muscle adaptation process however this are areas still being studied. ${ }^{12,13}$.

The HR and BP both had increased significantly from pre to post training. The aim of taking these parameters was to evaluate the intensity level of training given in this study. The light intensity training which was suggested for untrained bodybuilders would increase the heart rate about $60-70 \%$. However, in this study the increase was in a lower range suggesting heart rate arose mainly due to variety of subject's adaptation level and period of rest between each set. The BP increased in this study was due to the need to supply the muscle with enough blood throughout training and bodybuilding training increases peripheral resistance by muscle force compression to peripheral arteriole. ${ }^{15}$

In conclusion, there was a significant increase in CPK level and VAS from pre to post bodybuilding training in untrained bodybuilders. There was also a strong positive significant correlation between CPK and VAS in untrained bodybuilders.

Based on this study, it is highly suggested to use these indicators to monitor and evaluate the progress of bodybuilders in fitness centers. Besides that, the usage of VAS as first line indicator followed by CPK as second line indicator in fitness centers will help to identify the effectiveness of fitness programs provided as well as help in identifying overtraining status among bodybuilders. If the CPK level is above $10,000 \mathrm{U} / \mathrm{L}$ it is better to stop physical activity for some period of time as this level suggests the subject is at the verge of developing overtraining status.

\section{References}

1. Crameri RM, Aagaard P, Qvortrup K, Langberg H, Olesen J, Kjaer M. Myofibre damage in human skeletal muscle: effects of electrical stimulation versus voluntary 
contraction. J Physiol. 2007;583(1):36580.

2. Clarkson PM, Hubal MJ. Exercise-induced muscle damage in humans. Am J Phys Med Rehabil. 2002;81(11):S52-69.

3. Bloomer RJ. The role of nutritional supplements in the prevention and treatment of resistance exercise-induced skeletal muscle injury. J Sports Med. 2007;37(6):519-32.

4. Totsuka M, Nakaji S, Suzuki K, Sugawara $\mathrm{K}$, Sato K. Break point of serum creatine kinase release after endurance exercise. J Appl Physiol. 2002, 2002;93(4):1280-6.

5. Kenny J-E. Creatine kinase: how much is too much? Clinical Correlations, The New York University Langone Online Journal of Medicine. 2010. (Cited 2012 December 12) Available from: http:// www.clinicalcorrelations.org/? $\mathrm{p}=6560$.

6. Fusco A, Foglia A, Musarra F. The shoulder in sport: management, rehabilitation, and prevention. 1st ed. Philadelphia:Churchill Livingstone Elsevier. 2008.

7. Brancaccio P, Maffulli N, Limongelli FM. Creatine kinase monitoring in sport medicine. Br Med Bull 2007;8182(1):209-30.

8. Morandi L, Angelini C, Prelle A, Pini A, Grassi B, Bernardi G, et al. High plasma creatine kinase: review of the literature and proposal for a diagnostic algorithm. J Neurol Sci. 2006;27(5):303-11.

9. Paul GL, DeLany JP, Snook JT, Seifert JG, Kirby TE. Serum and urinary markers of skeletal muscle tissue damage after weight lifting exercise. Eur J Appl Physiol Occup Physiol. 1989;58(7):786-90.

10. Tidball JG. Inflammatory processes in muscle injury and repair. Am J Physiol, 2005;288(2):R345-53.

11. Baird MF, Graham SM, Baker JS, Bickerstaff GF. Creatine-kinase- and exercise-related muscle damage implications for muscle performance and recovery. J Nutr Metab. 2012;2012:960363.

12. Aoi W, Naito Y, Takanami Y, Kawai Y, Sakuma K, Ichikawa $\mathrm{H}$, et al. Oxidative stress and delayed-onset muscle damage after exercise. Free Radic Biol Med. 2004;37(4):480-7.

13. Allen DG, Lamb GD, Westerblad H. Skeletal muscle fatigue: cellular mechanisms. Physiol Rev. 2008;88(1):287-332.

14. Barbieri E, Sestili P. Reactive oxygen species in skeletal muscle signaling. J Signal Transduct. 2012;2012:982794

15. Pickett TC, Lewis RJ, Cash TF. Men, muscles, and body image: comparisons of competitive bodybuilders, weight trainers, and athletically active controls. Br J Sports Med. 2005;39(4):217-22. 